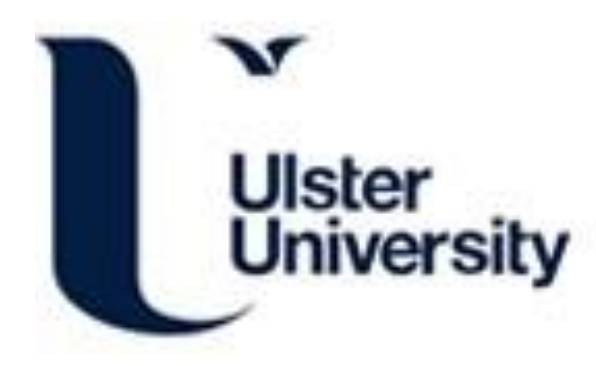

\title{
Effectiveness of flood early warning system from the perspective of experts and three affected communities in urban areas of Pakistan
}

Rana, I. A., Bhatti, S. S., \& Jamshed, A. (2020). Effectiveness of flood early warning system from the perspective of experts and three affected communities in urban areas of Pakistan. Environmental Hazards. https://doi.org/10.1080/17477891.2020.1751031

Link to publication record in Ulster University Research Portal

\author{
Published in: \\ Environmental Hazards
}

Publication Status:

Published online: 10/04/2020

DOI:

10.1080/17477891.2020.1751031

\section{Document Version}

Author Accepted version

\section{General rights}

Copyright for the publications made accessible via Ulster University's Research Portal is retained by the author(s) and / or other copyright owners and it is a condition of accessing these publications that users recognise and abide by the legal requirements associated with these rights.

\section{Take down policy}

The Research Portal is Ulster University's institutional repository that provides access to Ulster's research outputs. Every effort has been made to ensure that content in the Research Portal does not infringe any person's rights, or applicable UK laws. If you discover content in the Research Portal that you believe breaches copyright or violates any law, please contact pure-support@ulster.ac.uk. 
Effectiveness of flood early warning system from the perspective of experts and three affected communities in urban areas of Pakistan

\author{
Irfan Ahmad Rana ${ }^{1}$, Saad Saleem Bhatti ${ }^{2}$, Ali Jamshed ${ }^{3}$,
}

${ }^{1}$ Corresponding Author, Department of Urban and Regional Planning, National University of Sciences and Technology (NUST), Islamabad, Pakistan, iarana@nit.nust.edu.pk

${ }^{2}$ School of Geography and Environmental Sciences, Ulster University, United Kingdom s.bhatti@ulster.ac.uk;

${ }^{3}$ Institute of Spatial and Regional Planning (IREUS), University of Stuttgart, Germany, ali.jamshed@ireus.uni-stuttgart.de 


\title{
Effectiveness of flood early warning system from the perspective of experts and three affected communities in urban areas of Pakistan
}

\begin{abstract}
Pakistan has faced frequent flash and riverine flooding in the recent decades.. An effective Early Warning System (EWS) can help save lives and reduce damages. This study evaluates the effectiveness of flood EWS from the perspectives of local experts/institutions and communities. Interviews and consultations with the local experts (13 officials from government and other concerned departments) were carried out to understand the institutional challenges in communicating early warnings, whereas three flood-prone communities from different-sized cities (Rawalpindi, Sialkot and Muzaffargarh) were surveyed. A total of 210 samples were collected through household questionnaire surveys to assess their understanding of the local warning system. The analysis revealed that almost half of the community respondents did not receive a warning when last time the flood occurred. Variations were also observed regarding the main source of early warning in the three communities. This study identifies institutional challenges, such as lack of (1) resources to keep an EWS equipment operational; (2) community trust; and (3) proper guidelines to communicate warnings. The study calls for an immediate revision of strategies to communicate early warnings to the end-users and to incorporate their feedback in designing/redesigning the early warning mechanisms.
\end{abstract}

Keywords: flood risk management; preparedness; risk communication; risk perception; urban flooding.

\section{Introduction}

Climate change and increased risk of disasters have amplified the vulnerability of human and ecological systems. Evidence suggests that the frequency and intensity of natural hazards, especially flooding, have increased significantly (Douglas et al. 2008; Jamshed et al. 2017). According to an estimate, 1,507 flood events ${ }^{1}$ have been reported between 1980 and 2000, which increased to 2,860 between 2000 and 2018 (EM-DAT 2018). Climate change is linked as the major reason behind this escalation (Hirabayashi et al. 2013; Kundzewicz et al. 2013; Dankers and Feyen 2008; Jongman et al. 2018). As a result, more population is now exposed to floods that have not only increased the risk but also unveiled various vulnerabilities in the socio-ecological systems. The distribution of vulnerabilities and risk is uneven, where countries in the Global South are more vulnerable due to limited capacities to cope and adapt (Mirza 2003; Mertz et al. 2009). Both climate change and disaster risk scientists, therefore, find interest in developing strategies to reduce the disaster risk and adapt to the climate change impacts. These strategies include various coping and adaptive methods involving both soft and hard elements. Early Warning System (EWS) has emerged

\footnotetext{
${ }^{1}$ An event is classified as a disaster when ten (10) or more people are reported killed, or hundred (100) or more people are reported affected, or declaration of a state of emergency or call for an international assistance.
} 
as one of the key measures adopted by several countries and is considered a vital component of Disaster Risk Reduction (DRR) for saving lives.

Pakistan, a developing country in South Asia, has an estimated population of 207 million, with an annual Gross Domestic Product (GDP) growth rate of 5.5\%, and is ranked $147^{\text {th }}$ on human development index (PBS 2017; The World Bank 2015; Jahan 2015). The country is facing multiple natural hazards frequently due to its distinct climatic conditions, geography, meteorology, and climate change, which makes it one of the most vulnerable countries in the world (Mueller et al. 2014; Kazi 2014). Flooding is the most common hazard and Pakistan has experienced around 2 floods every year between 1970 and 2015 (EM-DAT 2017). In the last ten years (2000-2010), the country has faced worst floods in the history destroying millions of houses, displacing huge population and causing damages of billions of dollars (Nadeem et al. 2014). The severity of urban flooding in terms of life and capital losses can be attributed to the weak disaster management system, reactive instead of a proactive approach to disaster management, rapid urbanisation and population growth, low literacy levels, construction in floodplains, poor forecasting and ineffective early warning systems (Abbas et al. 2015; Rana and Routray 2016). The country was ranked $1^{\text {st }}$ in 2010 and $5^{\text {th }}$ in 2015 on Global Climate Risk Index (Kreft et al. 2015).

The amount of work done to explore the human/social aspect of early warning systems has been quite limited in developing countries, especially Pakistan. This study aims at: (1) exploring the effectiveness of EWS through review of associated policies and practices, and assessment and analysis of experts' and communities' perspectives; (2) understanding and identifying the shortcomings and challenges in the existing flood disaster management system in relation to EWS; and (3) propose measures to improve the process of disaster management with regards to development and implementation of EWS. Pakistan is chosen as a case study area to examine the overall outlook of EWS implementation strategies and policies from an institutional perspective, whereas three flood-prone communities (Dhok Ratta, Rawalpindi; Hajipura, Sialkot; and Khangarh, Muzaffargarh) in the province of Punjab in the country are selected to further assess and analyse the societal aspect of EWS.

\section{Early Warning Systems}

Early warning is an elementary part of DRR strategy (Rogers and Tsirkunov 2010). Early warning is generally defined as "...provision of information on an emerging dangerous circumstance where that information can enable action in advance to reduce the risks involved" (Basher 2006). In the context of hazards, it is defined as

"an integrated system of hazard monitoring, forecasting and prediction, disaster risk assessment, communication and preparedness activities systems and processes that enables individuals, communities, governments, businesses and others to take timely action to reduce disaster risks in advance of hazardous events" (UNISDR 2009).

The definition has two primary sides, first is more technical and the second involves human factor. Twigg (2003) suggested that the human factor is extremely important as early warning system fails due to poor communication and lack of preparedness among the 
community. Basher (2006) also highlighted that an efficient EWS should not only be scientifically and technically sound, but also incorporate risks faced by the exposed communities, depending upon their hazard and socioeconomic characteristics, and is able to suggest short-term or long-term mitigation measures. He further highlighted four main elements of community-based EWS namely knowledge about risk, continuous monitoring and warning delivery, clear and fast communication, and response capacities (Basher 2006). In the context of hazards, the efficiency of early warning systems can be measured in terms of lives saved and reduction in losses which can result in lowering the vulnerability of the population and decrease the disaster risk (Garcia and Fearnley 2012; Leon et al. 2006). An ideal EWS should consist of i) an operational warning system, ii) end-users, iii) regular testing and consequent modification, iv) regular monitoring and hazard change detection, $v$ ) collection and analyses, vi) transmission of the warning message, vii) feedback and all-clear signal warning, and viii) review and re-test system with subsequent modifications in the system (Foster 1987).

\subsection{The EWS approaches}

An EWS is commonly conceptualised as an arrangement where the warnings are generated based on the outputs of forecasting models and/or on-ground observations, and the contingency plans are implemented by the concerned authorities (government and/or others regulatory bodies). It is, however, observed that an 'unofficial' system is more prevalent in the communities where the warning information is usually coming through onground observations and is dispersed via personal networks of people. The key difference between both the systems is that of the 'technical/specialist knowledge' versus the 'local knowledge'. The two concepts are usually termed as: (1) official (top-down); and (2) unofficial (bottom-up) warning approaches. There are obvious advantages and disadvantages of both the systems which can be exploited to improve the effectiveness of an EWS.

The functioning of the two EWS concepts in the context of floods is illustrated in Figure 1. As with most of the early warning systems, the community satisfaction and effectiveness of the official flood warning systems have always been questionable, primarily, in terms of public acceptance and adherence to the warnings issued by the regulatory authorities (Parker and Handmer, 1998). The official warning systems, however, bring certain features that on occasions are dubious in the unofficial systems, such as credibility of the warnings, outreach, control over rumours and fake news, and safety-related procedures. The unofficial or local systems, on the other hand, are considered more effective at disseminating the warnings with greater specificity because of local knowledge, are at times more accurate (on-ground observations by the local informers), and of somewhat higher local credibility. 


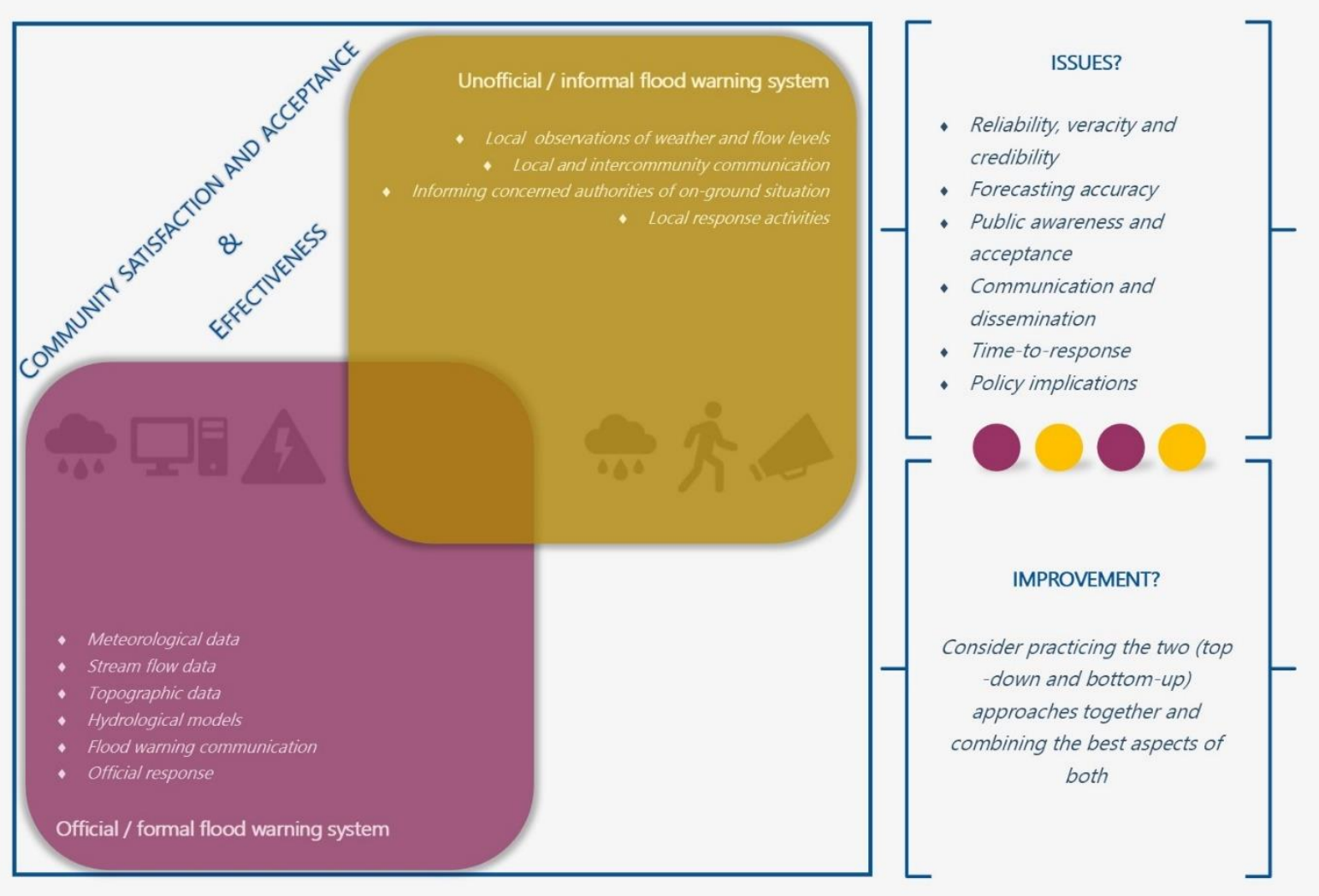

Figure 1. The two approaches to flood warning systems, the associated issues and improvement potential.

\subsection{An EWS and society}

The EWS is extensively studied in disaster risk science to safeguard the exposed communities. However, the efficiency of EWSs differs because of socioeconomic conditions, cultural practices and trust in the government. Alfieri et al. (2012) studied the European operational warning systems for water-related hazards, especially floods, and focused on its technical factors. Abon et al. (2012), on the other hand, developed a community-based monitoring for a flood EWS by installing rain gauges in houses and using the data to model the rain-flood relationship. Parker et al. (2009), however, argues that community response against flooding is usually poor due to limited understanding of EWS, mistrust in local institutions, and lack of participation in flood risk reduction measures. Further, Smith et al. (2017) highlighted that failure in EWS was due to limited lead time available for early warnings. Cools et al. (2016) investigated flood early warning in three different countries by comparing the method of forecasting and maximum lead time. Birkmann et al. (2008) studied various socio-economic factors that influence the decision and behaviour in case of tsunami early warning.

In order to make early warning effective, it needs to be combined with the systematic risk reduction measures. Rogers and Tsirkunov (2010) argued that critical infrastructures are vital for warning systems to be effective. The critical infrastructures include safe evacuation routes, shelters for humans, secure hospitals, etc. More importantly, they indicated that 
people's perception and willingness to act on an early warning must be embedded when designing the whole system (Rogers and Tsirkunov 2010). Cools et al. (2016) suggested engaging key stakeholders in designing the whole system to achieve a higher response rate. Innocenti (2014) also highlights the importance of local knowledge for early warning systems. These studies, however, did not look into stakeholder's perception of existing warning systems which are based on various social and cultural norms. The perception of stakeholders (both communities and authorities) about existing early warning process is imperative to improve the whole process, as well as to provide information which can better integrate it with the systematic risk reduction measures.

\section{Methodology}

The methodology to conduct this study comprises four main processes: (1) review of the existing situation in the study area (Pakistan) with regard to the role of EWS in disaster management; (2) assessment and analysis of perspectives of local experts and communities (three flood-prone communities in the province of Punjab, Pakistan) in relation to success/failure/shortcomings of EWS; (3) identify and highlight the challenges that existing EWS and associated systems face; and (4) propose appropriate measures for improving the practicality and effectiveness of EWS for disaster management in the study area (Figure 2).

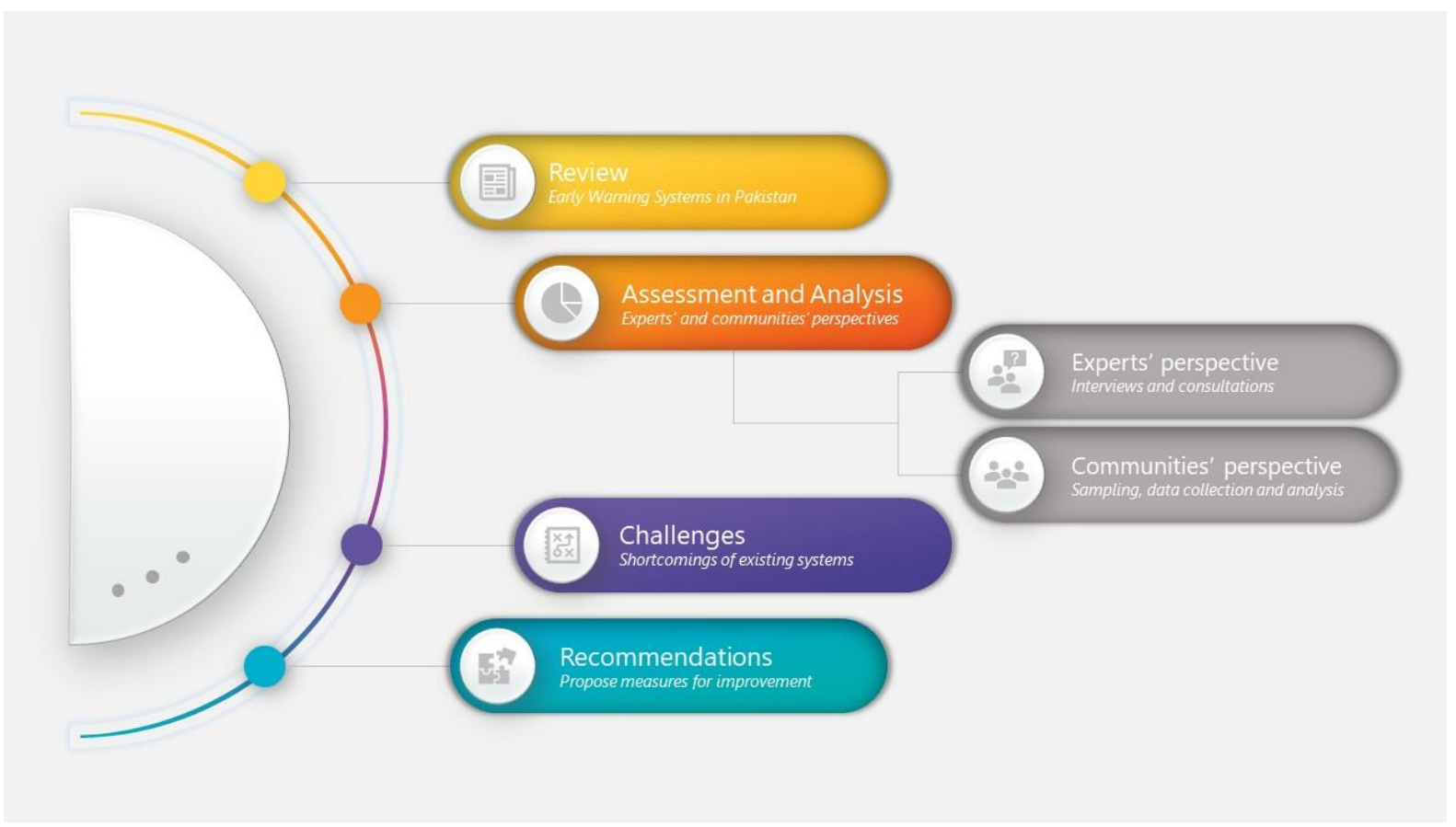

Figure 2. An overview of the methodology to carry out this study.

\subsection{A review of early warning systems in Pakistan}

In Pakistan, disaster management was based on a reactive approach until 2005. Hyogo Framework of Action provided the paradigm shift from reactive to a more proactive approach. Considering this, the National Disaster Management Authority (NDMA), Pakistan developed a national disaster management plan in 2012 for the next ten years, a subsection of which includes a national multi-hazard EWS plan (National Disaster Management Authority NDMA 2012). The multi-hazard EWS plan seeks vulnerability reduction through 
strengthening EWS's capacity, at national, provincial and district governments, along with local community organisations, NGOs, local businesses, and stakeholder involved in the DRR (NDMA 2012). The plan also identifies several activities from baseline studies, identification of hazards, planning of short- and long-term projects, as well as installation and monitoring of warning systems. The allocated budget for long-term and short-term early warning projects was US\$188.5 million (NDMA 2012). The plan provides the institutional framework for hazard forecasting and dissemination of warning at the federal, provincial and local levels. The main player in EWS is supposed to be the Pakistan Meteorological Department (PMD), which directly communicates warnings to the District Disaster Management Authority (DDMA). However, DDMA does not exist in any of the districts in Pakistan and there is no custodian of EWS at the local level (Ahmed 2013; Jamshed 2015; Mukhtar 2018). When compared with the guidelines of Sendai Framework, it can be found that a lot of emphases have been put on the element of monitoring and warning services. Almost $90 \%$ of the project's budgeted costs are devoted to this element, conceived as technologyextensive and expensive while downplaying the other elements of people's centered EWS (Mukhtar 2018).

Provincial Disaster Management Authority (PDMA), Punjab has developed a satellite-based integrated EWS that brings together major stakeholders (meteorological department, irrigation department, emergency services) at the provincial level (Shahzad et al 2018). Mukhtar (2018) reviewed the multi-hazard EWS plan and suggested that two essential parts of EWS, risk knowledge and response capacities, have not been acknowledged. The study argued that the forecasting system exists and the communication of early warning is a oneway process - the community involvement is weak in the entire design of the existing EWS. Mukhtar (2018) further contended that a people-centred approach is completely missing. In the case of flood hazards, there are several institutions involved in collecting information and its dissemination which has complicated the response process for communities at risk. Jamshed (2015) indicated that flood early warning can help save moveable assets but still, there is a large proportion of people who do not understand and respond to flood warnings. Rana and Routray $(2016,2018)$ assessed the vulnerability of urban communities to floods where early warning was explored as one of the components in their study. Mustafa et al. (2015) studied the gender-based perspective of flood EWS in Pakistan considering four aspects of the people-centered warning system (risk knowledge, monitoring and warning service, dissemination and communications, and response capability) - they found that all four fall short on the gender-sensitive EWS. Turner et al. (2014) studied floods of 2010 in Pakistan, and indicated that remote warnings (TV, radio) do not have significant influence on instigating community preparedness, while face-to-face warning increases the likelihood that community would take preparedness measures.

Pakistan still uses a technocratic approach, which limits public involvement in decision making. This creates a communication gap, distrust among communities and local government. Official early warnings are made up of scientific jargon, which further limits communities at risk for taking appropriate preparedness measures (Mustafa et al. 2015). 
Thus, it has become imperative to determine the effectiveness of EWS, and identify key challenges faced by the institutions.

\subsection{Perspective of experts and communities}

Interviews and consultations with the local experts were carried out in early 2015 to have their opinion on the successes or failures of EWS in the country. Total 13 experts from various departments, most of them having an experience of more than 5 years in their respective fields, were consulted (Table 1). The information collected through these meetings helped establishing the thematic areas and to identify the key challenges for an effective EWS in Pakistan. 
Table 1. A roundup of the local experts consulted to record their opinions about EWS.

\begin{tabular}{|c|c|c|c|}
\hline & Expert's designation & Department & $\begin{array}{r}\text { Work } \\
\text { experience } \\
\text { (years) }\end{array}$ \\
\hline 1 & Director Administration & Provincial Disaster Management Authority (PDMA), Punjab & 20 \\
\hline 2 & Director Operations & Provincial Disaster Management Authority (PDMA), Punjab & 15 \\
\hline 3 & Assistant Director & $\begin{array}{l}\text { Flood Monitoring Cell, Provincial Disaster Management } \\
\text { Authority (PDMA), Punjab }\end{array}$ & 5 \\
\hline 4 & Sub Divisional Officer & River Diversion, Irrigation Department, Govt. of Punjab & 6 \\
\hline 5 & $\begin{array}{l}\text { Town Officer (Planning } \\
\text { and Coordination) }\end{array}$ & Town Municipal Administration, Rawal Town, Rawalpindi & 4 \\
\hline 6 & Sub Divisional Officer & Irrigation Department, Rawalpindi Division & 8 \\
\hline 7 & Chief Executive Officer & NGO & 25 \\
\hline 8 & $\begin{array}{l}\text { Tehsil Officer (Planning } \\
\text { and Coordination) }\end{array}$ & Town Municipal Administration, Sialkot & 26 \\
\hline 9 & Sub Divisional Officer & Irrigation Department, Sialkot & 7 \\
\hline 10 & Field Officer & NGO & 8 \\
\hline 11 & $\begin{array}{l}\text { Tehsil Officer (Planning } \\
\text { and Coordination) }\end{array}$ & Town Municipal Administration, Muzaffargarh & 9 \\
\hline 12 & Sub Divisional Officer & Irrigation Department, Muzaffargarh & 4 \\
\hline 13 & Supervisor & NGO & 11 \\
\hline
\end{tabular}

In addition, communities' viewpoint on EWS was captured through a questionnaire survey that was carried out during June and July 2015. Further details of this activity are given in the following subsections.

\subsubsection{Selection of case study areas, and their profile}

The province of Punjab in Pakistan was selected as the case study region for this research for the reasons that: (1) it hosts more than half of Pakistan's population (the largest province of the country in terms of population); and (2) five major large rivers pass from this province (Jamshed 2015) where several urban and rural areas are highly prone to flood hazards. To address one of the key objectives of this study, understanding and identifying the shortcomings and challenges in the existing flood disaster management system in relation to EWS, the selection of the case study area involved three stages: (1) identifying cities/towns in the province of Punjab, Pakistan that are highly prone to flooding; (2) shortlisting three cities, each to be categorised as a large, medium or small town (an urban settlement with more than 1 million population was categorised as large; $0.5-1$ million as medium and less than 0.5 million as a small town); and (3) selecting a community within the towns selected in stage 2 that has experienced flood-related damages in the past. Considering these criteria, one community (union council, the smallest administrative unit in Pakistan) each from Rawalpindi, Sialkot, and Muzaffargarh cities was selected as 
representative of large, medium and small towns, respectively (Figure 3). These included Dhok Ratta in Rawalpindi, Hajipura in Sialkot and Khangarh in Muzaffargarh which are not only at high flood risk (NDMA, 2012) but have also suffered flood-related damages in the past (as quoted by the PDMA).

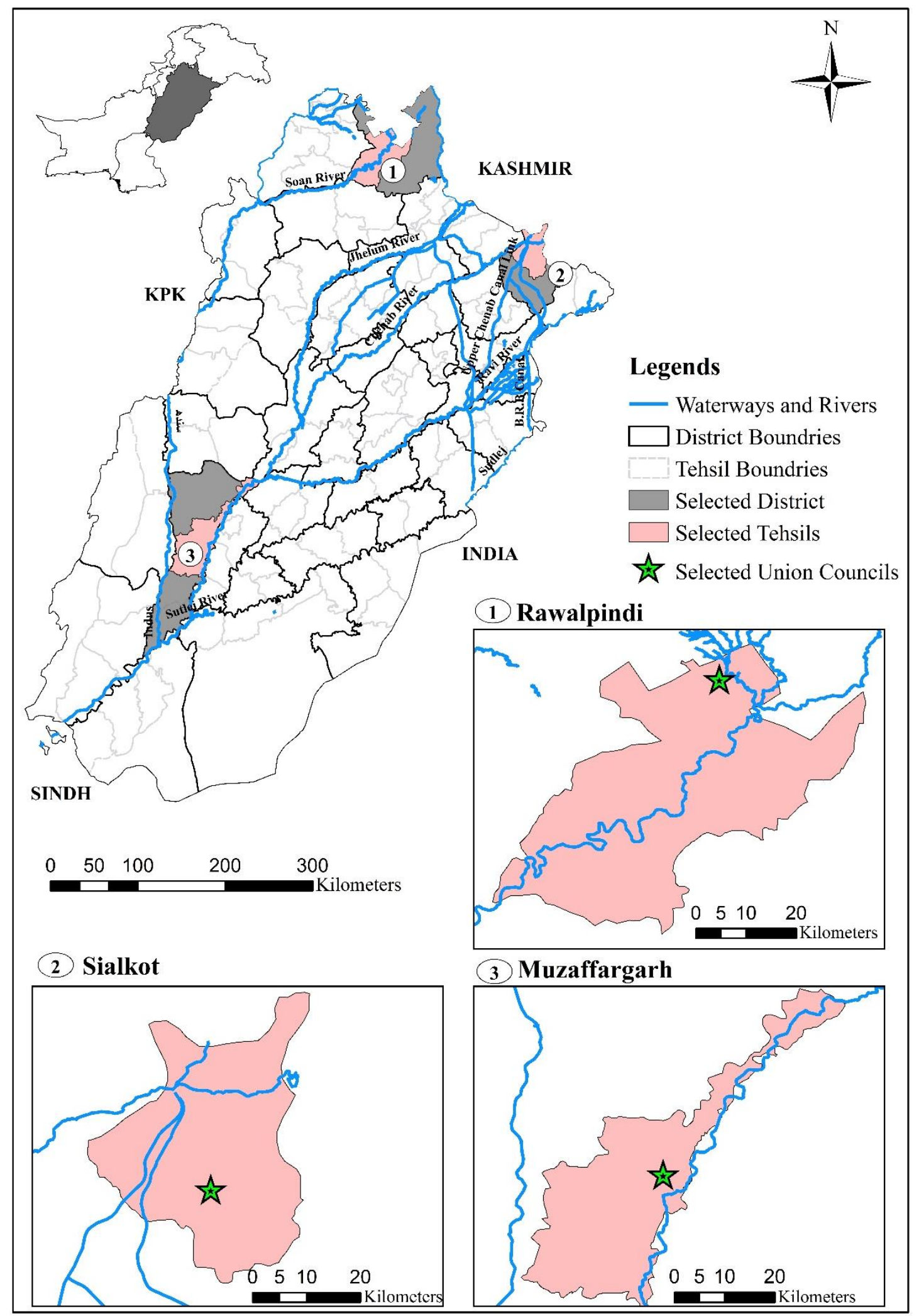


Figure 3: The geographic location of the towns selected as case study area in the province of Punjab, Pakistan: (1) Rawalpindi; (2) Sialkot; and (3) Muzaffargarh.

\subsubsection{Questionnaire development, sampling and data collection}

A questionnaire was designed to collect information regarding current awareness and knowledge level of the selected communities. The respondents were asked a series of questions regarding presence and functional EWS, understanding about the operational procedures of EWS and trusting the warnings or information issued by the government institutions, and sources of early warnings in their communities. The questionnaire mainly comprised close-ended (nominal / categories) questions, except for understanding and trust, which was based on a 5-point Likert scale.

According to the Punjab Development Statistics 2014, the population of the three selected communities was 12,867 households (Punjab Bureau of Statistics, 2014). Using Cochran's sampling method, a minimum of 194 samples were required, at $95 \%$ confidence level and 0.07 precision. These were proportionately divided with 64,69 and 61 from each community in the Rawalpindi, Sialkot and Muzaffargarh cities. However, 70 samples (questionnaire responses) were collected in the field from each community, bringing the total to 210 .

A total of three survey teams were deployed in the case study areas during June and July, 2015 for data collection. The responses to the questions were recorded by the teams through asking questions from the respondents - the collected data was later entered and stored digitally for further analysis.

\subsubsection{Data analysis}

The data collected from two sources (local experts and communities) was analysed separately: 1) content analysis was done and findings from the experts/key informant interviews were categorised under thematic areas to identify the key challenges for effective EWS in Pakistan; and 2) descriptive statistics were used to analyse the local communities' perception of EWS in the selected study areas. Based on the analysis, issues and challenges hindering effective EWS in the communities were identified, which can be targeted to improve the EWS and thus reduce the urban flood risk.

\section{Results and discussion}

An EWS is one of the key components of the broader hazards and disaster management systems. It is also one of the determinants of how well a community can withstand a disaster - a good EWS essentially helps to prepare for the worst at the right place and at the right time. Although early warning systems are not yet efficient and sophisticated enough to comprehend all the different types of hazards and disasters (e.g. earthquakes) but still they have proven effective in reducing the risk of life losses in case of floods (Garcia and Fearnley 2012). An absence of such a system not only endangers the life of people in the event of a calamity but also poses risk to the relief efforts - e.g. no one would know if another flood is following the one that has already caused damage to the life and property. 
A good EWS not only analyses the data and generates the results (in a timely fashion), but also communicates the outcomes in an effective way so that the communities take proper advantage of the information. In case of floods, an EWS can only be effective if it is capable of properly forecasting and simulating the water flows, identifying the communities at risk, and communicating those risks in a clearly understandable way to those communities and the concerned disaster management departments. This study not only examined the effectiveness of flood warning systems in three communities in the cities of Rawalpindi, Sialkot and Muzaffargarh in Pakistan, but also evaluated the outcomes of consultations with the key informants (officials from government and other concerned departments) on the challenges that the EWS faces in the country.

\subsection{Flood early warning systems in Punjab, Pakistan - effective or not?}

Based on the survey data collected in this study in three flood-prone communities in the province of Punjab, Pakistan, it was found that the majority of households in Rawalpindi did not receive any warning about last floods (2001 and 2005) - the warning situation was however opposite in the cities of Sialkot and Muzaffargarh (Figure 4). This finding was quite interesting, which indicated that the EWS was working well for some areas and not too good for the others. This shows that a significant percentage of the population has not received any kind of early warning, which can have serious implications for flood risk management in urban communities. Whether there was some deficiency in the EWS itself or the community did not understand/took seriously the warnings generated and communicated by the system? - the question was further investigated. 


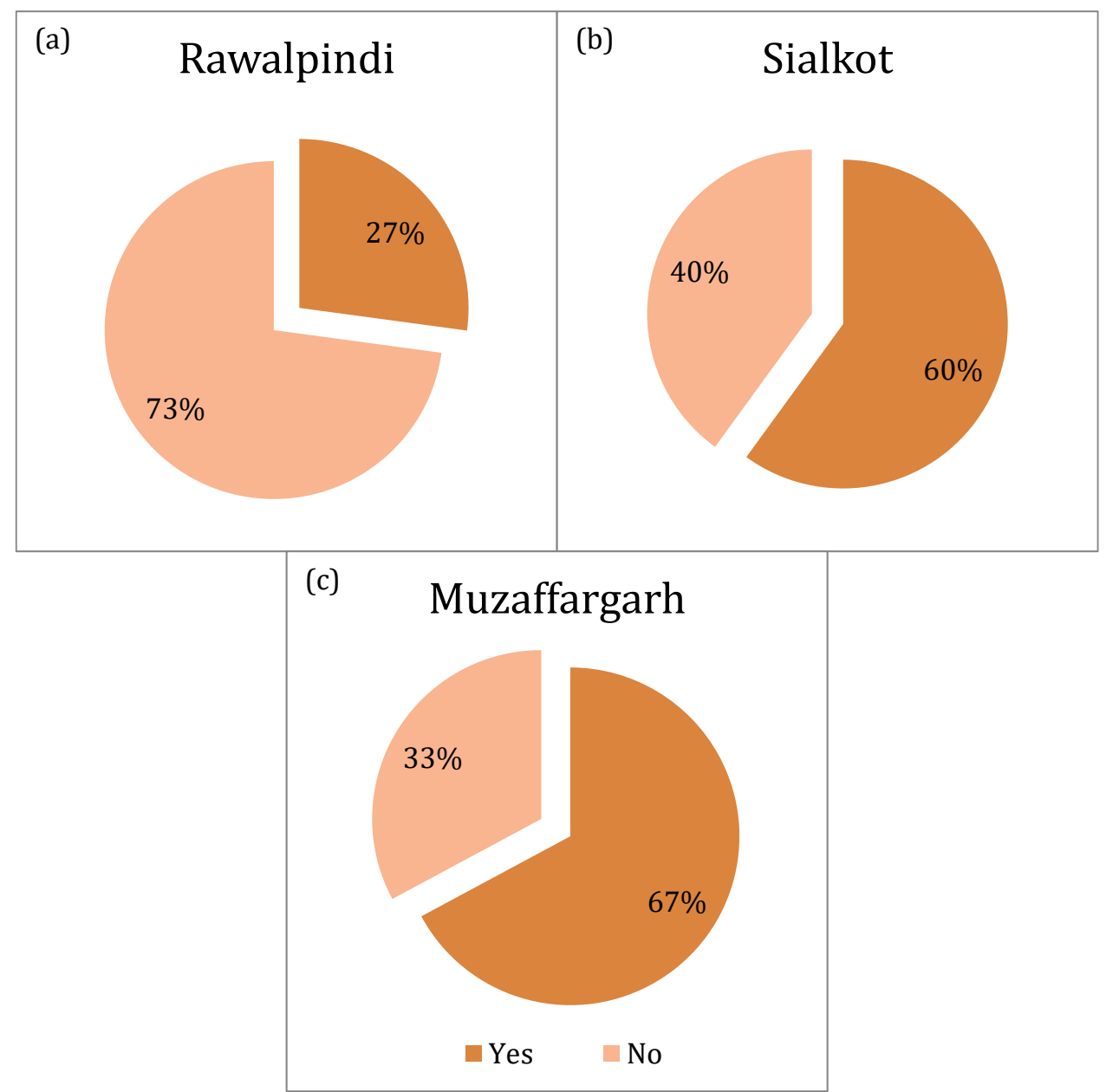

Figure 4. Flood early warning received by households in flood-prone communities in (a) Rawalpindi, (b) Sialkot and (c) Muzaffargarh cities during last flood ( $n=70$ in each city).

More interesting results awaited when the people's understanding of the warning systems was analysed - most of the respondents showed distrust in government agencies, which held them back from seeking help and understanding the warning system. Even with a fully functional and tested EWS, the desired outcomes could not be achieved if the communities do not understand, or undermine the significance of the warning. The results indicated that around 63, and 60 percent of the surveyed households in Sialkot and Muzaffargarh areas, respectively, had high to very high understanding of the national warning system (Figure 5). This level of understanding (high to very high) of the warning system was found in just 13 percent of the surveyed households in Rawalpindi city. This finding clearly indicates that even if the flood EWS was perfect in this situation (which is not the case here, its shortcomings are discussed below), the people in Rawalpindi area would not respond to the warning due to lack of understanding about the system. Hence, there is a need to improve the local awareness about EWS in all the communities (not just Rawalpindi) - not only should efforts be made to improve the local understanding of the EWS, but the level of this understanding should also be assessed from time to time to see if the people are still alert and take the warnings seriously or not. 


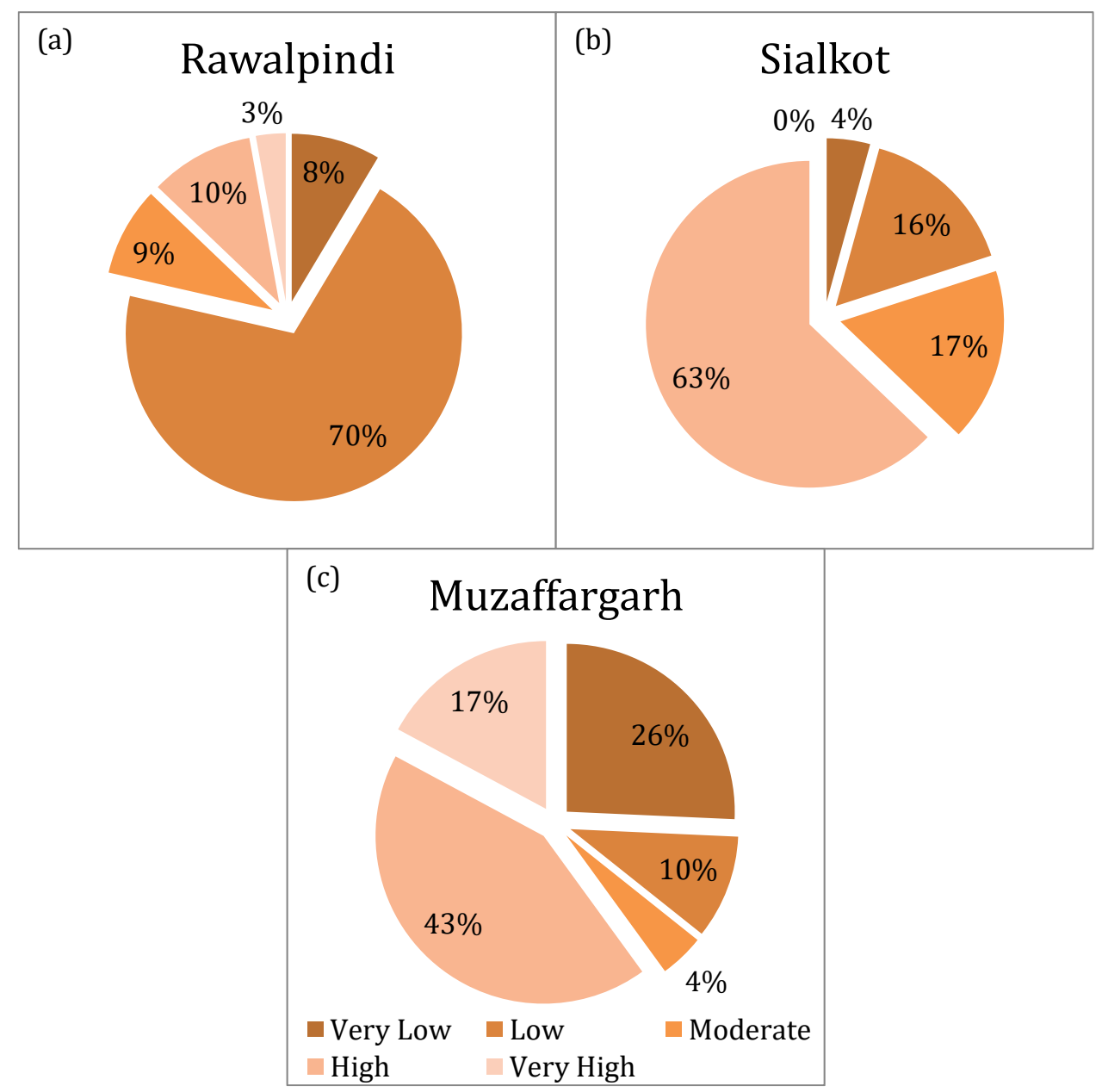

Figure 5. Peoples' understanding about national warning system in flood-prone communities in (a) Rawalpindi, (b) Sialkot and (c) Muzaffargarh cities ( $n=70$ in each city).

Another important aspect about communicating a warning is the medium used for dissemination of information. In the three communities studied, five different modes or channels of flood warning communication were identified namely District Authority, Local Authority, Police, Mosque and Army. According to the respondents, all the channels, with varying degrees, disseminated early warnings except Army which did not contribute to this cause in Rawalpindi and Sialkot areas (Figure 6). Interestingly, any single source of communication cannot be identified as an efficient means for issuing flood warnings based on the results. The most common sources of warning were the District and Local authorities. Despite an absence of district level disaster management authorities, district and local administrations act on ad-hoc basis in the situations where there is a need to announce flood warnings - they also try to avert the damaging consequences of the disaster in their own limited capacities. 


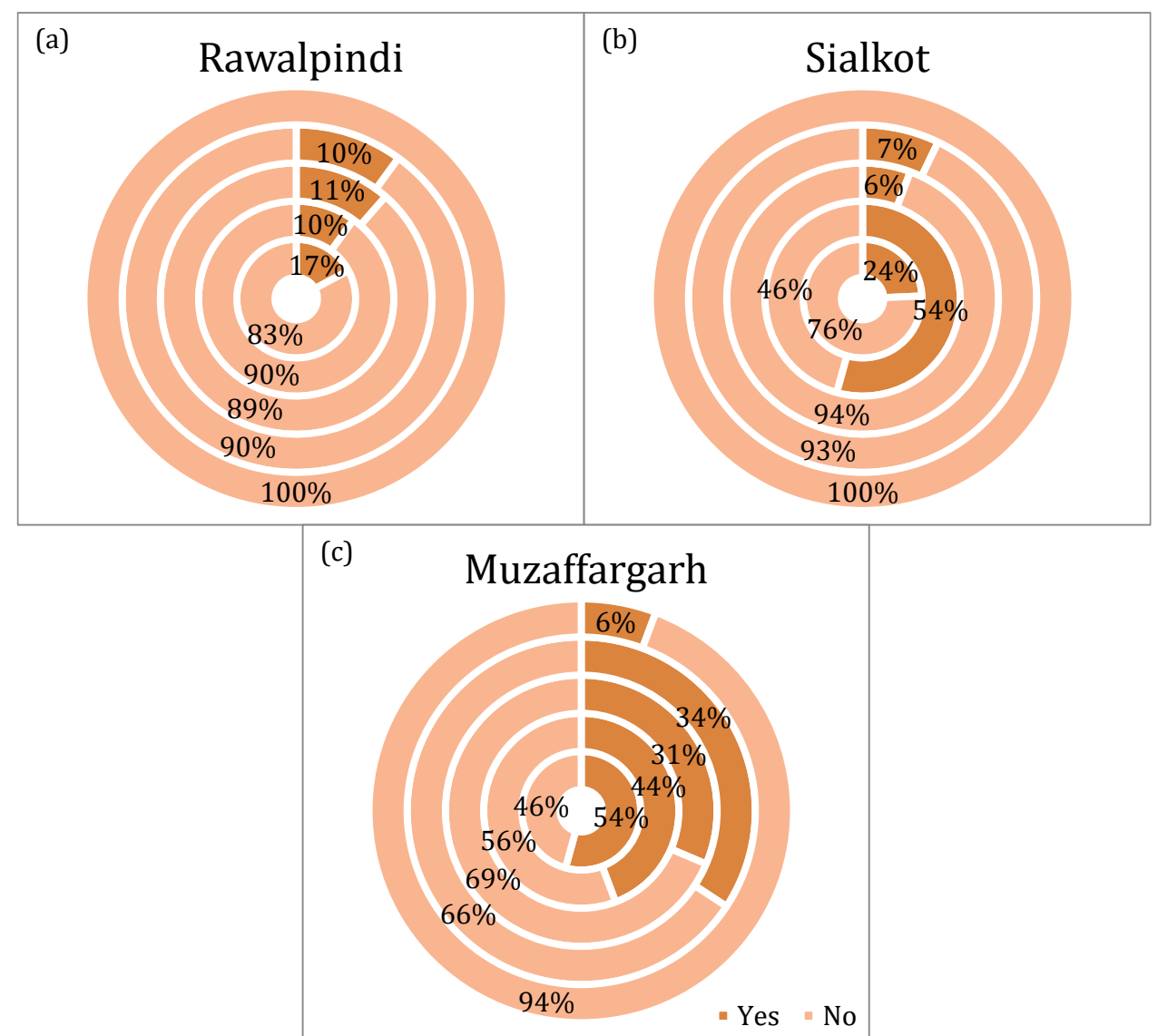

Figure 6. Peoples' perception about effectiveness of different sources of flood warning dissemination, inner to outer ring in order: District Authority, Local Authority, Police, Mosque and Army, in the surveyed flood-prone communities in (a) Rawalpindi, (b) Sialkot and (c) Muzaffargarh cities ( $n=70$ in each city).

Majority of the households and local officials did not even know that their locality was declared high flood risk area by NDMA, an indicator for poor risk communication and perception. Due to the ineffectiveness of local government, the community's trust has been lost. This distrust has embedded in the mindset of the exposed communities, leading to scepticism about the EWS itself. The public thinks that government gives seasonal warnings all the time. Some elders asserted that local administrations deliberately break the embankments without intimating directly exposed communities, just to save croplands of influential people or critical infrastructure from flooding. Households are very reluctant to relinquish their houses on the off-chance that flood might come. This shows poor risk perception of exposed communities which needs to be worked upon. As a remedial measure, communities choose some volunteers to sleep near embankments in order to safeguard and keep an eye on it. This precautionary measure was explicitly observed in Muzaffargarh.

The trust or mistrust of people in government's planning and policies also plays an important role in the community taking action on the warnings issued by the official department/s in case of a disaster. Majority of the local flood-prone communities in the three selected communities indicated very low level of trust in government's policies on 
DRR (Figure 7). Around 34, 9 and 10 percent of the respondents in Rawalpindi, Sialkot and Muzaffargarh areas, respectively, indicated moderate to high level of confidence in government's policies on disaster management. This finding is quite interesting - despite having a comparatively higher level of trust in the DRR policies of the government (Figure 7), a large number the respondents in Rawalpindi (compared to the other two selected cities) did not receive early warning of flood (Figure 4). This clearly indicates that although the people in this area were willing to act upon the warning, the system (or the EWS) did not work well at this particular instance. This distrust can be attributed to the failure of institutions in delivering timely early warning in the past which has caused havoc in selected urban communities. Another reason could be poor flood risk perception of the exposed communities (Rana and Routray, 2016). A dysfunctional or a non-trustworthy EWS, in this case, leads to this notion: will the people in Rawalpindi express the same level of trust in future warnings generated by this system?

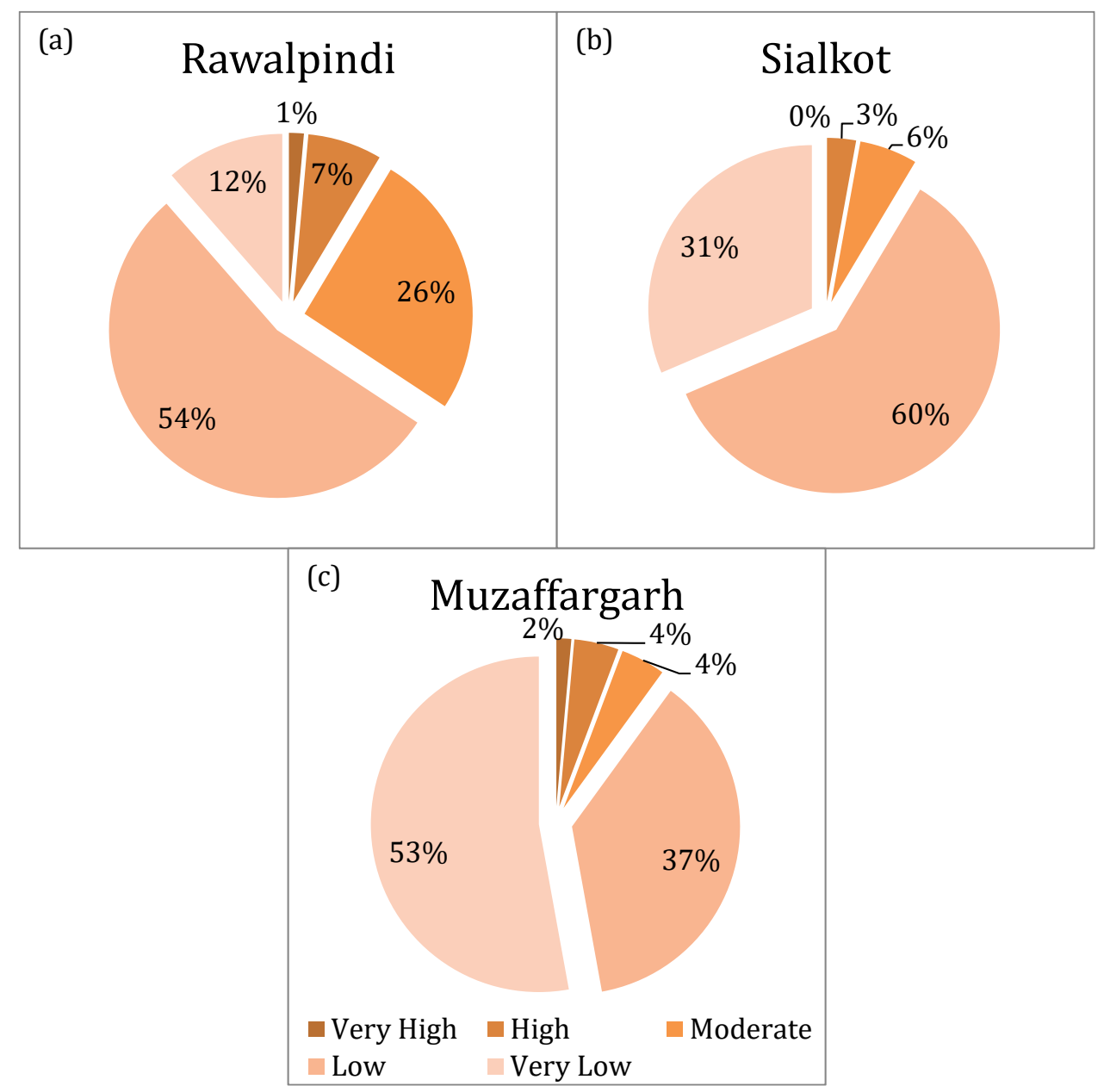

Figure 7. Peoples' trust in government policies on disaster risk reduction in flood-prone communities in (a) Rawalpindi, (b) Sialkot and (c) Muzaffargarh cities ( $n=70$ in each city).

Peoples' level of trust in disaster-related warnings not only depends on the credibility of the EWS but also on the medium used for announcing the warnings to the community. Another aspect of this is increasing the local awareness about EWS, and about the importance of acting on the warnings seriously. The medium used for increasing such awareness and 
disseminating disaster warnings is the most important component of the whole DRR system - a credible medium/means of announcement helps build the trust of the community in EWS as well as in the actions taken by the government to minimise the risk and potential damage. The usual means for flood warning dissemination and increasing flood awareness in the study area comprise television, telephone, radio, mobile phones, newspapers, pamphlets/brochures, social media, and banners. However, all warning channels have their own limitations and advantages. When asked about the preferred source for warning communication and for increasing flood awareness, the respondents in Sialkot and Muzaffargarh areas responded almost similarly by putting relatively high preference $>70 \%$ agreement) on television, telephone, radio, mobile phones and newspapers as the preferred sources of communication (Figure 8). The response from the flood-prone community in Rawalpindi, however, did not look positive as the most preferred mode of warning communication (television) had just 50\% agreement with the next one (newspapers) having just $46 \%$ agreement (in comparison to more than $85 \%$ and $70 \%$ agreement in Sialkot and Muzaffargarh areas, respectively). This low level of agreement can be linked, to some extent, with the low number of households in Rawalpindi receiving warnings during the last flood event (Figure 4). Warnings disseminated through mobile phones are increasingly becoming common in developing countries. In Pakistan, mobile subscriptions per 100 persons grew from 7.96 to 72.55 from 2005 to 2018 (The World Bank, 2019), signifying the potential of such services that can be harnessed by the disaster management institutions. The least preferred mode of communication, according to the respondents in all three areas, is the social media. Although the online platform and social media provides one of the fastest means of information distribution, people in the flood-prone areas have either marginal or zero access to online facilities, or they do not trust the information given through the online medium. Nevertheless, the findings suggest that the concerned department/s should also focus on this important component of the system, the medium of information dissemination, so that the information is received by maximum number of households in and efficient and effective manner. The potential of communicating the warnings through mobile phones should be further exploited given the rise in mobile phone subscriptions in the country. 


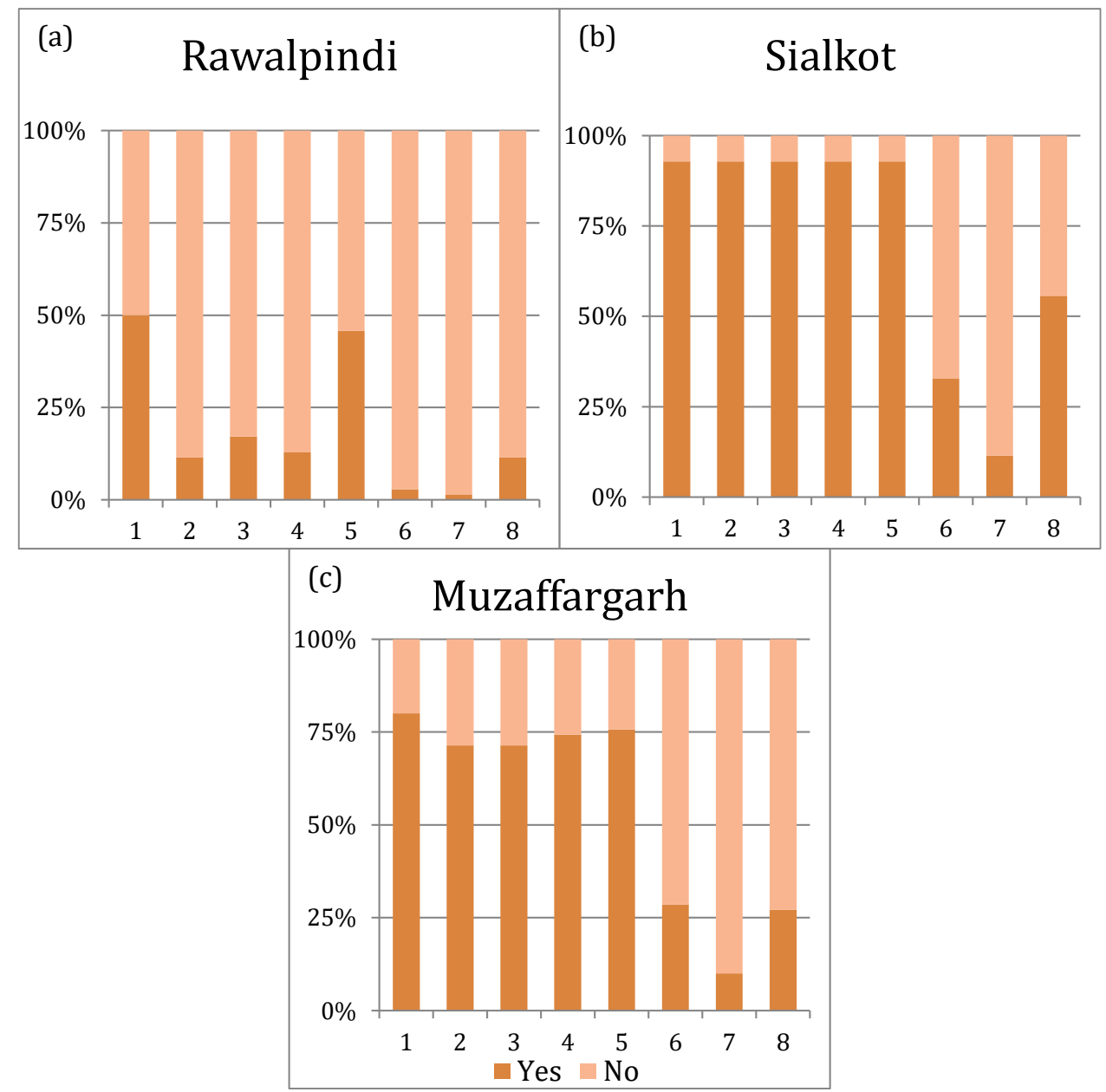

Figure 8. Peoples' preferred source for warning communication and for increasing flood awareness in flood-prone communities in (a) Rawalpindi, (b) Sialkot and (c) Muzaffargarh cities ( $n=70$ in each city) $-x$-axis labels (1) television, (2) telephone, (3) radio, (4) mobile phones, (5) newspapers, (6) pamphlets/brochures, and (7) social media, and (8) banners.

\subsection{Institutional challenges in effective early warning systems}

The foremost challenge faced by the local government, as identified in this study through consultations with the local experts, was to evacuate people from flood bound areas. Even when the early warning was communicated, people did not want to leave their homes. Officials of PDMA claimed that the Short Message Service (SMS) was also used to communicate the warning alerts to mobile phones of the people registered on the PDMA database, only to get a little response in terms of real evacuation. Another issue plaguing the effectiveness of EWS is the lack of communication within line departments. After the 18th amendment to the Constitution of Pakistan where powers have been devolved to the provincial governments, the provincial disaster management authorities are not legally bound to answer the NDMA. Consequently, the link between them has diminished over time. Moreover, neither the National and Provincial Disaster Management Authority disseminate knowledge to lower tiers, nor are they having any direct communications with the local or district administrations. As a result, the higher tier (NDMA/PDMAs) fails to recognise the issues of local authorities. Moreover, the National and Provincial governments 
have different and sometimes contrasting priorities, i.e. energy crisis, poverty and terrorism. Liaison and coordination thus need to be strengthened to overcome such shortcomings.

The EWS in Pakistan is following a top-down approach where the feedback from the society (people) is still missing. Disaster response begins from local level, but early warning initiated from federal level. Mere presence of such a warning system does not guarantee an effective flood risk reduction, it also requires proper policy processes and active local community participation for its success. "Not a perfect flood EWS in place" - the EWS, as well as the prediction and climate change models at PMD, are in a dire need of upgrading, according to the opinion of key informants interviewed in this study. The system is out of date and needs a complete overhaul as the warnings are not effectively disseminated to the communities; even if timely and appropriate warnings are generated, people do not respond to them in a serious way.

Results have shown that EWS is absolute in the field. The foremost issue was the lack of actual communication with some households. However, even if a warning is received, communities are not following the right procedures, possibly due to their inability to comprehend the meaning (severity) of the warnings and/or distrust in the local government. This shows a very serious problem for local institutions to effectively implement any development projects, let alone EWS. Interestingly, a number of mediums and channels of communication are available to the institutions, provided the warning messages remain consistent, that could be exploited to reach the in-danger communities.

\section{Conclusions and way forward}

DRR emphasises preparedness driven approaches over relief. An EWS is one of the major components of disaster preparedness. It is known to directly influence the preparedness level of the community and in the context of flooding, it has become integral for disaster risk management, and overall flood risk reduction. The basis for good EWS lies in effective forecasting, timely conveyance, and response mechanism in flood-prone communities. There is a need to integrate the top-down and bottom-up approaches of EWS where community involvement can play a pivotal role in the success of the overall system. A twoway communication is thus needed, otherwise only a small portion of recipients will react to the warnings. The results of this study have identified issues in EWS in Pakistan. Local experts believe that the data collection, processing, analysis, forecasting and prediction systems/methods at the PMD and other institutions responsible for disaster risk management in the country need upgradation. EWS is not quite understood by the flood prone urban communities and, therefore, is not relied upon by the households. Generally, in urban settings, households with weak socioeconomic backgrounds are settled in exposed areas, multiplying their vulnerability. Low literacy in the vulnerable communities influences their ability to fully understand EWS and adherence to the emergency protocols. However, this study only focuses on three urban communities, which cannot be generalised for whole cities. More advanced statistical analyses with larger samples can be performed to evaluate EWS in the country. Trust (in the EWS, warning alerts, government and local institutions), or 
lack thereof, is another vital under-researched component of an EWS, which needs to be examined in detail.

Although just three communities were focused upon to examine the effectiveness of EWS from a social/human perspective, it was quite evident and conclusive that the EWS developed and deployed in the country struggles in terms of its functionality and effectiveness. The key point presumably is the missing link between the technologically driven EWS and the more informal societal attitude. The challenge is the development and implementation of a society-inclusive approach where the disaster management institutions should learn and adapt (keeping in view the local requirements) from the successful flood warning systems implemented in other (developed / developing) countries. Nevertheless, a community-inclusive, functional, trustworthy and up to date system is needed in Pakistan along with proper channels for effective dissemination of early warnings.

A rational way forward could be: (1) to identify responsible disaster management authority and concerned organisations, streamline their jurisdictions, and devise mechanisms for effective and efficient flow of information between the stakeholders; (2) upgrade the EWS using advanced technological resources; (3) use communication means that are appropriate for each community (e.g. warning announcements by local authorities effective in one community might not be the best choice at another location where Mosques are abundant - information disseminated through Mosques in such a setting could be more effective); and (4) increase local awareness about the EWS and importance of taking any EWS generated warnings seriously.

\section{References}

Abbas, Azhar; Amjath-Babu, T. S.; Kächele, Harald; Müller, Klaus (2015): Non-structural flood risk mitigation under developing country conditions. An analysis on the determinants of willingness to pay for flood insurance in rural Pakistan. In Nat Hazards 75 (3), pp. 2119-2135. DOI: 10.1007/s11069-014-1415-x.

Abon, Catherine C.; Primo C. David, Carlos; Tabios, Guillermo Q. (2012): Community-based monitoring for flood early warning system. In Disaster Prev and Management 21 (1), pp. 85-96. DOI: 10.1108/09653561211202728.

Ahmed, Zubair (2013): Disaster risks and disaster management policies and practices in Pakistan. A critical analysis of Disaster Management Act 2010 of Pakistan. In International Journal of Disaster Risk Reduction 4, pp.15-20. DOI: 10.1016/j.ijdrr.2013.03.003.

Alfieri, Lorenzo; Salamon, Peter; Pappenberger, Florian; Wetterhall, Fredrik; Thielen, Jutta (2012): Operational early warning systems for water-related hazards in Europe. In Environmental Science \& Policy 21, pp. 35-49. DOI: 10.1016/j.envsci.2012.01.008.

Basher, Reid (2006): Global early warning systems for natural hazards. Systematic and peoplecentred. In Philosophical transactions. Series A, Mathematical, physical, and engineering sciences 364 (1845), pp. 2167-2182. DOI: 10.1098/rsta.2006.1819.

Birkmann, Joern; Setiadi, Neysa; Gerbert, N. (Eds.) (2008): Socio-economic vulnerability assessment at the local level in context of tsunami early warning and evacuation 
planning in the city of Padang, West Sumatra. International conference on tsunami warning. Nusa Dua, Indonesia, 12-14 November. Nusa Dua, Indonesia.

Collins, Matthew L.; Kapucu, Naim (2008): Early warning systems and disaster preparedness and response in local government. In Disaster Prev and Management 17 (5), pp. 587600. DOI: 10.1108/09653560810918621.

Cools, Jan; Innocenti, Demetrio; O'Brien, Sarah (2016): Lessons from flood early warning systems. In Environmental Science \& Policy 58, pp. 117-122. DOI: 10.1016/j.envsci.2016.01.006.

Dankers, Rutger; Feyen, Luc (2008): Climate change impact on flood hazard in Europe. An assessment based on high-resolution climate simulations. In J. Geophys. Res. 113 (D19), p. 224. DOI: 10.1029/2007JD009719.

Douglas, Ian; Alam, Kurshid; Maghenda, Maryanne; Mcdonnell, Yasmin; Mclean, Louise; Campbell, Jack (2008): Unjust waters. Climate change, flooding and the urban poor in Africa. In Environment and Urbanization 20 (1), pp. 187-205. DOI: 10.1177/0956247808089156.

EM-DAT (2017): Disaster Country Profiles. Pakistan. Universite catholique de Louvain (UCL); Centre for Research on the Epidemiology of Disasters (CRED). Brussels. Available online at http://www.emdat.be/country_profile/index.html, checked on 2/2/2018.

EM-DAT (2018): Disaster damages. Universite catholique de Louvain (UCL); Centre for Research on the Epidemiology of Disasters (CRED). Brussels. Available online at https://www.emdat.be/emdat_db/, checked on 11/27/2018.

Foster, H. D. (1987). Disaster warning systems: learning from failure. In Information Systems: Failure Analysis (pp. 3-13). Springer, Berlin, Heidelberg.

Garcia, Carolina; Fearnley, Carina J. (2012): Evaluating critical links in early warning systems for natural hazards. In Environmental Hazards 11 (2), pp. 123-137. DOI: 10.1080/17477891.2011.609877.

Hirabayashi, Yukiko; Mahendran, Roobavannan; Koirala, Sujan; Konoshima, Lisako; Yamazaki, Dai; Watanabe, Satoshi et al. (2013): Global flood risk under climate change. In Nature Climate change 3 (9), pp. 816-821. DOI: 10.1038/nclimate1911.

Innocenti, Demetrio (2014): When Science Meets Policy: Enhancing Governance and Management of Disaster Risks. In Philippe Quevauviller (Ed.): Hydrometeorological Hazards. Chichester, UK: John Wiley \& Sons, Ltd.

Jahan, Selima (2015): Human Development Report 2015. Work for human development. New York, NY, USA: United Nations Development Programme (Human development report, 2015).

Jamshed, Ali (2015): Assessing vulnerability and capacity of flood affected communities in Punjab, Pakistan. Case study: district Jhang and Muzaffargarh. Master. Universität Stuttgart, Stuttgart. Available online at http://dx.doi.org/10.18419/opus-8959.

Jamshed, Ali; Rana, Irfan Ahmad; Birkmann, Joern; Nadeem, Obaidullah (2017): Changes in Vulnerability and Response Capacities of Rural Communities After Extreme Events. Case of Major Floods of 2010 and 2014 in Pakistan. In J. of Extr. Even. 4 (3), p. 1750013. DOI: 10.1142/S2345737617500130. 
Jongman, Brenden; Winsemius, Hessel C.; Fraser, Stuart A.; Muis, Sanne; Ward, Philip J. (2018): Assessment and Adaptation to Climate Change Related Flood Risks. In Natural Hazard Science, pp. 1-29. DOI: 10.1093/acrefore/9780199389407.013.278.

Kazi, Asadullah (2014): A review of the assessment and mitigation of floods in Sindh, Pakistan. In Nat Hazards 70 (1), pp. 839-864. DOI: 10.1007/s11069-013-0850-4.

Kreft, Sönke; Eckstein, David; Dorsch, Lukas; Fischer, Livia (2015): Global Climate Risk Index 2016. Who Suffers Most From Extreme Weather Events? Weather-related Loss Events in 2014 and 1995 to 2014. With assistance of Munich RE. Bonn: Germanwatch NordSüd Initiative Available online at http://germanwatch.org/en/download/13503.pdf, checked on 9/20/2016.

Kundzewicz, Zbigniew W.; Kanae, Shinjiro; Seneviratne, Sonia I.; Handmer, John; Nicholls, Neville; Peduzzi, Pascal et al. (2013): Flood risk and climate change. Global and regional perspectives. In Hydrological Sciences Journal 59 (1), pp. 1-28. DOI: 10.1080/02626667.2013.857411.

Leon, J.C.V de; Bogardi, Janos J.; Dannenmann, S.; Basher, R. (2006): Early Warning Systems in the context of Disaster Risk Management. In Entwicklung \& Ländlicher Raum 2, pp. 23-25. Available online at http://www.eird.org/cd/indm/documentos/46fad12d0a62e5.38742613.pdf.

Mertz, Ole; Halsnaes, Kirsten; Olesen, Jørgen E.; Rasmussen, Kjeld (2009): Adaptation to climate change in developing countries. In Environmental management 43 (5), pp. 743-752. DOI: 10.1007/s00267-008-9259-3.

Mirza, M. Monirul Qader (2003): Climate change and extreme weather events: can developing countries adapt? In Climate Policy 3 (3), pp. 233-248. DOI: 10.3763/cpol.2003.0330.

Mueller, V.; Gray, C.; Kosec, K. (2014): Heat Stress Increases Long-term Human Migration in Rural Pakistan. In Nature climate change 4, pp. 182-185. DOI: 10.1038/nclimate2103.

Mukhtar, Rabiya (2018): Review of National Multi-Hazard Early Warning System Plan of Pakistan in context with Sendai Framework for Disaster Risk Reduction. In Procedia Engineering 212, pp. 206-213. DOI: 10.1016/j.proeng.2018.01.027.

Mustafa, Daanish; Gioli, Giovanna; Qazi, Suleman; Waraich, Rizwana; Rehman, Abdul; Zahoor, Rashda (2015): Gendering flood early warning systems. The case of Pakistan. In Environmental Hazards 14 (4), pp. 312-328. DOI: 10.1080/17477891.2015.1075859.

Nadeem, Obaidullah; Jamshed, Ali; Hameed, Rizwan; Anjum, Ghulam Abbas; Khan, Muhammad Arif (2014): Post-Flood Rehabilitation of Affected Communities by NGOs in Punjab, Pakistan-Learning Lessons for Future. In Journal of Faculty of Engineering \& Technology 21 (1), pp. 1-20.

National Disaster Management Authority NDMA (2012): National Disaster Management Plan2012. Islamabad: National Disaster Management Authority Pakistan NDMA. Available online at http://www.ndma.gov.pk/ex/Documents/ndmp.zip., checked on 10/4/2015.

Pakistan Bureau of Statistics PBS (2017): Province wise Provisional Results of Census. Edited by Ministry of Statistics. Pakistan Bureau of Statistics. Islamabad. Available online at http://www.pbs.gov.pk/sites/default/files/PAKISTAN\%20TEHSIL\%20WISE\%20FOR\%2 OWEB\%20CENSUS_2017.pdf, checked on 2/13/2018.

Parker, Dennis J.; Handmer, John W (1998): The Role of Unofficial Flood Warning Systems. In Journal of Contingencies and Crisis Management, 6(1), pp. 45-60. DOI: 


\section{$10.1111 / 1468-5973.00067$}

Parker, D. J.; Priest, S. J.; Tapsell, S. M. (2009): Understanding and enhancing the public's behavioural response to flood warning information. In Met. Apps 16 (1), pp. 103-114. DOI: 10.1002/met.119.

Punjab Bureau of Statistics (2014): Punjab Development Statistics 2014, Lahore, available at: http://www.bos.gop.pk/publicationreports.

Rana, Irfan Ahmad; Routray, Jayant K. (2016): Actual vis-à-vis perceived risk of flood prone urban communities in Pakistan. In International Journal of Disaster Risk Reduction 19, pp. 366-378. DOI: 10.1016/j.ijdrr.2016.08.028.

Rana, Irfan Ahmad; Routray, Jayant K. (2018): Multidimensional Model for Vulnerability Assessment of Urban Flooding. An Empirical Study in Pakistan. In Int J Disaster Risk Sci 9 (3), pp. 359-375. DOI: 10.1007/s13753-018-0179-4.

Rogers, D.; Tsirkunov, V. (2010): Cost and Benefits of Early Warning Systems. United Nations International Strategy for Disaster Reduction UNISDR; The World Bank. Geneva, Switzerland (Contributing Paper to the Global Assessment Report on Disaster Risk Reduction). Available online at https://www.preventionweb.net/english/hyogo/gar/2011/en/bgdocs/Rogers_\&_Tsir kunov_2011.pdf.

Smith, Paul J.; Brown, Sarah; Dugar, Sumit (2017): Community-based early warning systems for flood risk mitigation in Nepal. In Nat. Hazards Earth Syst. Sci. 17 (3), pp. 423-437. DOI: 10.5194/nhess-17-423-2017.

The World Bank (2019): World Bank Open Data, available at: https://data.worldbank.org/indicator/IT.CEL.SETS.P2?locations=PK.

The World Bank (2015): Pakistan. Country Snapshot. The World Bank Group. Washington, DC (100119). Available online at http://documents.worldbank.org/curated/en/619971467987825539/pdf/100119WP-PUBLIC-Box393225B-Pakistan-country-snapshot.pdf, checked on 8/16/2016.

Turner, Ginger; Said, Farah; Afzal, Uzma; Campbell, Karen (2014): The Effect of Early Flood Warnings on Mitigation and Recovery During the 2010 Pakistan Floods. In Zinta Zommers, Ashbindu Singh (Eds.): Reducing disaster. Early warning systems for climate change / edited by Zinta Zommers, Ashbindu Singh. Berlin: Springer, pp. 249-264.

Twigg, John (2003): The Human Factor in Early Warnings. Risk Perception and Appropriate Communications. In Jochen Zschau, Andreas Küppers (Eds.): Early warning systems for natural disaster reduction. Berlin: Springer, pp. 19-26.

United Nations International Strategy for Disaster Reduction UNISDR (2009): UNISDR Terminology on Disaster Risk Reduction. United Nations International Strategy for Disaster Reduction UNISDR. Geneva. Available online at https://www.unisdr.org/files/7817_UNISDRTerminologyEnglish.pdf, checked on $3 / 19 / 2018$.

Zia, Asim; Wagner, Courtney Hammond (2015): Mainstreaming Early Warning Systems in Development and Planning Processes. Multilevel Implementation of Sendai Framework in Indus and Sahel. In Int J Disaster Risk Sci 6 (2), pp. 189-199. DOI: 10.1007/s13753-015-0048-3. 